This item was submitted to Loughborough's Research Repository by the author.

Items in Figshare are protected by copyright, with all rights reserved, unless otherwise indicated.

\title{
Design and construction of large-area flexible printed-circuit automotive electrical interconnection harnesses
}

PLEASE CITE THE PUBLISHED VERSION

http://dx.doi.org/10.1243/09544070JAUTO1175

PUBLISHER

Professional Engineering Publishing (now Sage) and IMechE (๑ The authors)

VERSION

VoR (Version of Record)

LICENCE

CC BY-NC-ND 4.0

\section{REPOSITORY RECORD}

Webb, D. Patrick, Wayne A. Jaggernauth, Michael C.W. Cottrill, Paul J. Palmer, Andrew A. West, and Paul P. Conway. 2019. "Design and Construction of Large-area Flexible Printed-circuit Automotive Electrical Interconnection Harnesses". figshare. https://hdl.handle.net/2134/7703. 
This item was submitted to Loughborough's Institutional Repository (https://dspace.lboro.ac.uk/) by the author and is made available under the following Creative Commons Licence conditions.

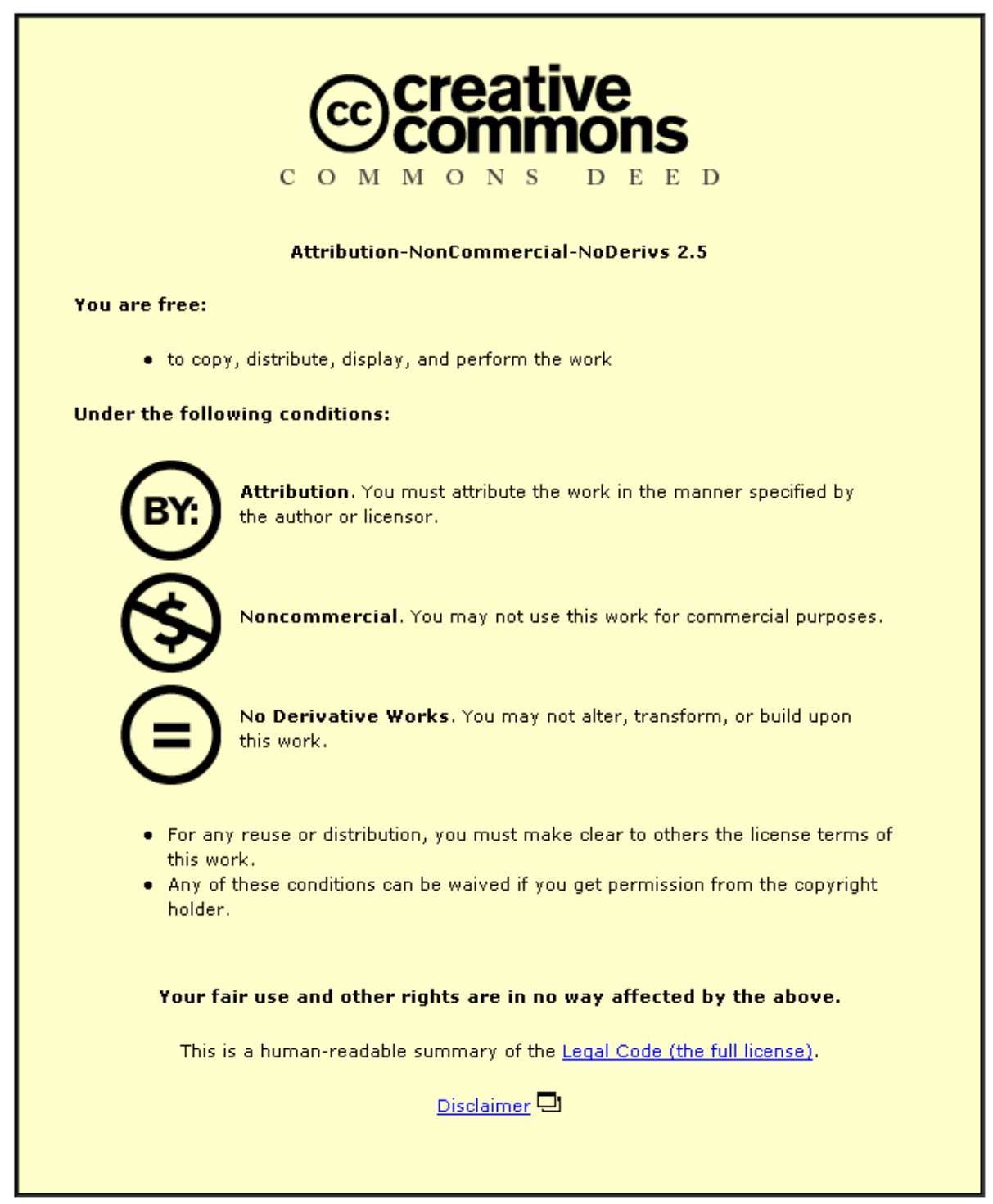

For the full text of this licence, please go to: http://creativecommons.org/licenses/by-nc-nd/2.5/ 


\title{
Design and construction of large-area flexible printed- circuit automotive electrical interconnection harnesses
}

D P Webb*, W A Jaggernauth, M C W Cottrill, P J Palmer, A A West, and P P Conway

Wolfson School of Mechanical and Manufacturing Engineering, Loughborough University, Loughborough, Leicestershire, UK

The manuscript was received on 20 February 2009 and was accepted after revision for publication on 8 January 2010.

DOI: 10.1243/09544070JAUTO1175

\begin{abstract}
The replacement of automotive wiring harnesses with large-area flexible printed circuits (FPCs) would help to reduce the vehicle weight and emissions. To help clarify what a future large-area FPC interconnection harness should be capable of, a detailed design exercise to meet the engineering specification of the instrument panel wiring harness of a specific midrange passenger car was carried out. To demonstrate the added value of using an FPC, intelligence in the form of active circuitry was incorporated in the designs.

Two generic architectural concepts were pursued. The first, a single large-area FPC, supported the wire harness geometry, all point-to-point interconnections, and current ratings up to $4 \mathrm{~A}$. However, the panel size was too large to be manufactured on existing automotive FPC process lines. The second, intended to be a collection of smaller FPCs that could be manufactured on existing automotive FPC process lines, was found not to be practical as originally conceived.

A physical implementation of the single large-area FPC design was made in stages at different company sites using various pieces of equipment, some of which are not normally used for FPC or electrical circuit manufacture. Modified versions of the equipment could be used to create a large-area automotive FPC manufacturing line.
\end{abstract}

Keywords: automotive wiring harnesses, large-area flexible printed circuits, vehicle weight, emissions

\section{INTRODUCTION}

Modern cars carry an increasing number of electrical and electronic devices. These include safety systems such as airbags and associated sensors, driving assistance systems such as cruise control and parking sensors, and comfort systems such as seat adjustment motors and entertainment devices. It has been estimated that electrical systems form 25 per cent by value of a typical car [1] , and this proportion is expected to continue to rise.

The electrical power and signal transmission requirements in a vehicle are met by the wiring harness. Increasing electrical demands leads to

*Corresponding author: Wolfson School of Mechanical and Manufacturing Engineering, Loughborough University, Loughborough, Leicestershire LE11 3TU, UK.

email:D.P.Webb@lboro.ac.uk increasing harness weight and complexity. In highend passenger cars the total length of wire used can exceed $4 \mathrm{~km}$ [1], and there may be over 350 connectors and nearly 1500 cut leads (number of circuits) [2]. At the same time there is unrelenting pressure to improve automobile fuel efficiency. The European Commission has proposed legislation to limit emissions from passenger cars and other light vehicles to $120 \mathrm{~g} / \mathrm{km}$ by 2012 [3]. This represents a cut over the current average of 25 per cent. The US Senate has recently approved a bill to enforce an across-the-board fuel efficiency of $35 \mathrm{mile} / \mathrm{gal}$ by 2020 [4].

One of the major factors in the vehicle fuel efficiency is the weight. With each additional $50 \mathrm{kgf}$ load, fuel consumption increases by 0.21 per $100 \mathrm{~km}$ travelled on a fine-tuned modern passenger car [1]. Replacement of wire with flexible printed circuits (FPCs) is an option for the industry to reduce the 
weight $[5,6]$, and a weight reduction of up to 70 per cent has been quoted [5]. This is possible because the weight of copper required to carry a given current through an FPC track is in principle smaller than that for a typical round wire used in an automotive harness. The difference is due to the larger surface-area-to-volume ratio and hence more efficient heat dissipation of the track [5]. FPCs are in fact well established in the automotive industry and have been in use in cars since the late 1960s [7], particularly for interconnection of the instrument cluster. The paper by Cottrill et al. [7] contains an introduction to automotive FPC construction and manufacture. However, in order to replace the wire harness to any significant extent, much larger circuits than have been manufactured up to now will be required. While the area of a typical modern instrument cluster circuit is around $500 \mathrm{~mm} \times$ $250 \mathrm{~mm}$ [7], estimates within the industry place the area of an FPC intended to replace the instrument panel (IP) wire harness at up to $2 \mathrm{~m}$ by $10 \mathrm{~m}$. Scaling up the capability of the current automotive FPC manufacturing processes and infrastructure to make such large circuits is a significant challenge.

The technical and business case issues involved in the use of large-area FPCs in mass market cars were examined during the course of the 2 year Flexelec project $[\mathbf{7}, 8-11]$, funded by the UK government through the Engineering and Physical Sciences Research Council and the Department of Trade and Industry. Four companies representing the different parts of the automotive electrical interconnect supply chain took part, including In2Connect Ltd (automotive FPC manufacturer, formerly Pressac Ltd) as the lead partner, and Loughborough University as the academic partner. The project had the aim of establishing what a large-area FPC automotive harness and the manufacturing line necessary to make it might look like.

For cost estimation in the project a production volume of around $1 \times 10^{6}$ circuits per annum, representing the requirement of two typical midrange models, was assumed. The financial work showed that the investment costs and manufacturing cost per unit are sensitive to the details of the design of an FPC harness $[\mathbf{7}, 8]$. However, the design specifications of a future large-area FPC automotive harness are not clear. The FPC is not envisaged to be a drop-in replacement for wire, and some redesign of the vehicle and its electrical system both to take advantage of and to accommodate the FPC would be required.

To address the issue of uncertainty in design, four concepts or construction options were formulated, and the process assessment and costing evaluation exercises were undertaken with reference to each option in turn. In order to prove the practicality of the concepts a detailed design exercise was also undertaken, and a physical embodiment of one design constructed. The detailed designs are referred to here as demonstrators, and the physical embodiment as a space model. In this work the design specification for the two demonstrators is presented and justified. Also described are the design process, the software tools used, and the construction of the space model. The demonstrators are critically assessed, and conclusions are drawn for the architecture and manufacture of future large-area FPC automotive harnesses.

\section{BACKGROUND}

The mass automotive market is mature, with fixed consumer expectations on the price and stable market volume. There is therefore strong pressure to improve the manufacturing efficiency and to reduce supplier costs, as cost reductions are a major contributor to improvements in profits. Consequently a prospective FPC harness not only must be lighter than an equivalent wire harness but also must cost less. However, an FPC harness can add value in other ways apart from weight saving. Some of the relative advantages and disadvantages of FPC versus wire for large-area automotive electrical interconnection are compared below.

The FPC advantages compared with wire are as follows.

1. Intelligence. The electronics could be mounted and interconnected directly on an FPC harness. This would lead to efficiency improvements in vehicle design and assembly through integrating what are currently separate electronic modules with the harness.

2. Automated construction. An FPC can be made by automated processes which yield advantages in quality control and reliability. In contrast, wire harness assembly is largely manual, as described in section 2.

3. Efficient architecture. Connection between separate circuits requires splices with wire, as described in section 2. With an FPC, splices are not required, eliminating a level of interconnection and improving reliability.

4. Electrical performance. The FPC can be designed to give the required electrical performance, by specifying which circuits lie adjacent to each 
other, e.g. to reduce cross-talk or to increase heat dissipation. In a wire harness the positions of wires within the bundle cannot be specified [12].

5. Space saving. An FPC harness may save space over a wire harness through being able to conform to the surface of, for example, vehicle trim.

The FPC disadvantages compared with wire are as follows.

1. Infrastructure. The major disadvantage of an FPC is that dedicated infrastructure for large-area circuits does not already exist, while that for wire is well established. However, one of the findings of this work is that equipment with the required capability does already exist and could be converted.

2. Current-carrying capacity. The ability of flex to carry the high currents required for failure conditions such as motor stalls has not been demonstrated. Existing guidelines for flex address continuous operating currents [5].

3. Connectors. The range of connectors that would be required by a large-area FPC does not yet exist and would have to be developed and tested.

From the viewpoint of environmental impact the major advantage of an FPC over wire is the reduced fuel consumption of a vehicle due to the lighter weight of the FPC for the same current-carrying capacity, as previously noted. The energy cost of manufacture of the FPC is probably also smaller, owing to the reduced weight of copper. For end-oflife disassembly and treatment an FPC is likely to be easier to strip from the vehicle than wire is, because it is lighter and can be easily cut. For recycling, the materials mix of FPC and wire are likely to be similar, consisting of copper, a thermoplastic dielectric insulation material, and the materials of fasteners and connectors, mostly thermoplastics [13]. The lower copper content of the FPC is likely to make it less economically attractive to recover than for wire. In addition, the adhesive layers in the FPC may contaminate the thermoplastic content, also making it harder to recycle.

Various outputs of the Flexelec project have already been published, addressing questions such as the following.

1. Materials choice. Which materials would give at least a 10 year life in service $[\mathbf{7}, 9]$ ?

2. Materials qualification standards and tests. Which of the current wire harness and FPC automotive standards are relevant? What should the pass criteria be $[\mathbf{9}]$ ?
3. Functional capability and future-proofing. What would the functional capabilities be (currentcarrying capability, signal transmission, electromagnetic compatibility properties)? Could emerging and projected automotive technologies be supported (e.g. automotive networks and $42 \mathrm{~V}$ electrical systems) $[\mathbf{1 0}, 11]$ ?

4. Processes and infrastructure. Which manufacturing processes can be used to manufacture a largearea FPC? What is current plant capable of and what development of new equipment would be required [7]?

5. Business case. What would be the likely investment required to meet the production target? What would be the price per unit and what is the financial risk $[\mathbf{8}]$ ?

Other issues identified but not treated in detail [7] were failure modes, consideration of an FPC harness from the viewpoint of the car manufacturer (e.g. assembly and integration into the vehicle), and the end user and service-and-repair network (ease of maintenance and maintenance costs). From the latter point of view it was noted that, while an FPC harness will be mostly invisible to the end user and so will not add any user-perceived value to the vehicle, it is important that there is no negative effect on perceived value, e.g. through the fact that FPC harnesses might become associated with higher repair costs. This consideration would tend to drive design trade-offs in the direction of higher reliability.

\section{AUTOMOTIVE WIRE HARNESS AND AUTOMOTIVE FPC CONSTRUCTION}

Automotive wire harnesses consist of bundles of wires taped or otherwise bound together so as to form a single component, with multiple arms shaped to fit into a chosen space in the vehicle. Shapers such as plastic stiffeners are incorporated to ensure that the harness adopts the required spatial configuration, together with fixings to hold it in place, and other additions such as foam to prevent rattle. Each arm is terminated with a connector, designed to plug into a particular electrical device, or to a connector on another wire harness. Wires are spliced together, e.g. for grounding, using components similar to connectors, called splice packs. Up to 10 per cent of circuits require a splice [14]. Some wires terminate in fixings to allow the wire to be grounded to the chassis. There are multiple wire harnesses in a typical vehicle, in areas such as the engine bay, cockpit, roof liner, doors, and trunk. The IP harness 


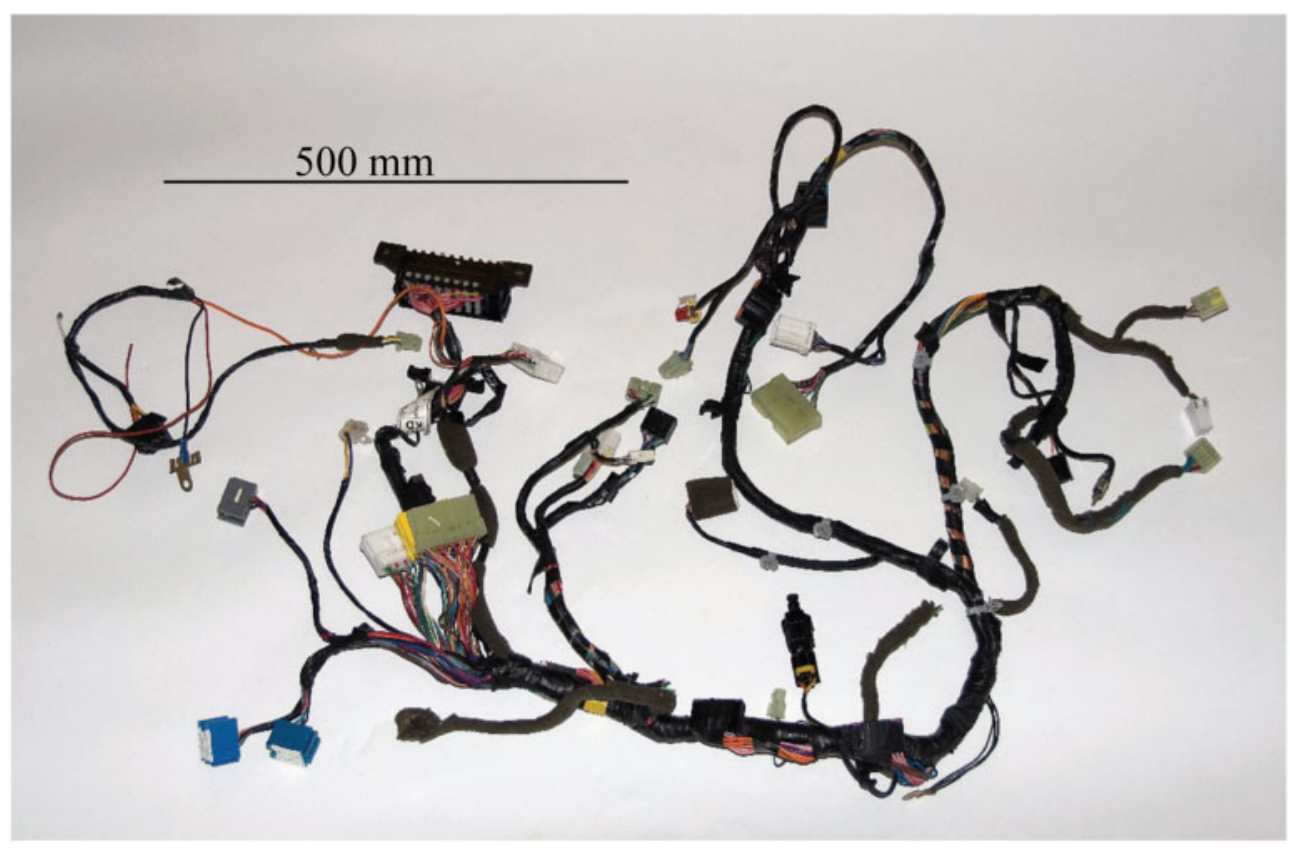

Fig. 1 Instrument panel harness for a Daewoo Nubira

is usually the most complex, servicing the array of switches and displays on the dashboard and steering column, and other devices such as the radio. A typical IP harness is shown in Fig. 1.

The environmental demands on a wire harness are determined by the zone of the car in which they are located. The IP harness is located in the passenger compartment, the most benign zone. Connectors are particularly prone to failure because of the physical nature of the electrical contacts and exposure to vibration and contaminants. The wire harness materials must be able to withstand the ambient conditions of the location zone.

The wire harness physical construction, arm lengths, and locations of connectors are specified by a layout diagram, while the electrical connectivity is given by a wire table. The layout diagram also specifies connector types and assigns wires to positions on connectors and splice packs. The wire table lists connections between connectors or splice packs and gives the circuit number, wire gauge, and insulation colour for each circuit connection. The specifications cover multiple harness-vehicle variants. Choice of wire gauge is determined by the current-carrying capacity required for a given circuit, including failure and transient conditions. This is laid down in a load analysis report. The determining factor is the maximum safe temperature rise of the wire above ambient. Guidance is given by standards such as BS AU 88a:1985 [15], which include derating of the current capacity of an individual wire when it is surrounded by other wires in the wire harness bundle. Wire harnesses are made to be physically robust and to survive assembly into the car by demanding techniques such as thread and pull. This means that there is a minimum wire gauge that is used to ensure mechanical integrity, typically AWG $22\left(0.35 \mathrm{~mm}^{2}\right)[\mathbf{1 6}]$.

A diagram of the cross-section of a typical automotive FPC is shown in Fig. 2. There is a base dielectric film, laminated on one side with copper foil which is patterned by etching to form the circuit traces. The circuitry is protected by a further laminated cover layer or coverlay of plastic dielectric film. A screen-printed dielectric ink can also be used. The most common plastics used for the base dielectric, in order of increasing robustness, are poly(ethylene terephthalate) (PET), poly(ethylene naphthalate) (PEN), and polyimide. PET costs the least, and its thermal degradation is likely to be slow enough to give it a 10 year lifetime in the ambient conditions in the passenger compartment zones of

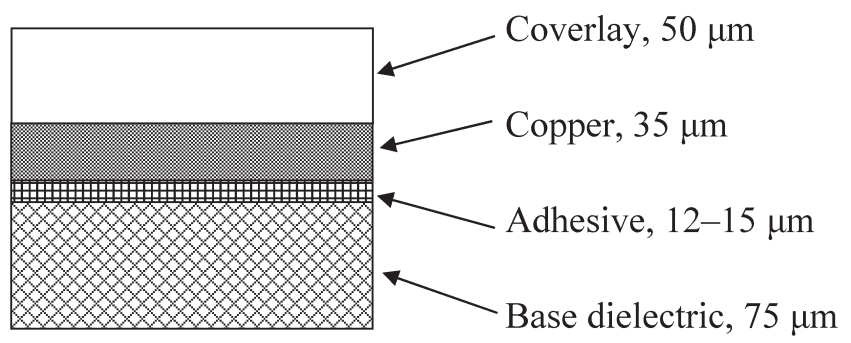

Fig. 2 Typical automotive FPC laminate structure 
the car (roof liner and cockpit) [7, 9]. The more expensive PEN is favoured for high-humidity areas where degradation includes hydrolytic attack, such as the 'wet' side of the passenger door [7]. Polyimide might be employed for applications requiring resistance to high temperatures, where for example the circuit may enter the engine compartment, but for the most part will not be considered because of its very high cost [7]. Because of the high temperatures it is unlikely FPCs will be used where the bulk of the circuit is in the engine compartment. Similar considerations of temperature stability and humidity resistance determine the choice of lamination adhesive.

Automotive FPCs are manufactured in reel-to-reel processes and are then profiled, i.e. cut out from the web by a variety of methods. Circuits are nested on panels to maximize material usage. The manufacturing processes for automotive FPCs, together with the implications of scaling up the circuit size capability for these processes, have been described in more detail by Cottrill et al. [7]. No automotive standards for FPC track width equivalent to those for wire gauges exist, although there are non-automotive standards [9]. There is no need to specify a minimum track width for robustness, since mechanical strength is provided by the base film. FPCs also obviate the need for splice packs.

Spliced connections are used extensively for attaching components to low-complexity automotive FPCs, and also for connecting two such circuits. Connection may be made either on a copper-tocopper basis, the crimp being used to clamp two opposing copper faces, or in an overlapping situation through windows in one of the circuits. Crimping has demonstrated high reliability provided that the crimps are correctly formed. The connection may be aided by a degree of cold welding between the copper and brass or tin surface of the crimp. Surface mount soldering of components to small- to medium-sized flexible circuits is also carried out, even where the base layer is the relatively temperature-sensitive PET. This is possible by the use of special low-thermal-mass pallets fitted with masks that expose only those areas with components. The difficulties of and possible solutions for transferring this approach to large circuits have been discussed by Cottrill et al. [7].

\section{CONSTRUCTION OPTIONS}

The construction options reflect different ways of segmenting an FPC harness so as to achieve compromises between reliability and cost [7]. The determinative factors are as follows.

1. Number of internal connectors. Each connector is seen as the source of a potential failure. Construction options requiring fewer internal connectors to join the different segments of an FPC harness are consequently more reliable.

2. Materials utilization efficiency. Smaller and more regularly shaped panels can be packed more closely on the web.

3. Area of complex circuitry. Restricting the area of the harness which requires more expensive processing techniques, such as fine-line circuitry, through-hole plating, and surface-mounted components, improves the line speed of reel-to-reel processing and reduces costs.

4. Maximum panel size. Restricting the maximum panel size, particularly the width, will reduce the capital costs of any new equipment required to process large-area FPC harnesses.

The construction options are described below and illustrated in Fig. 3.

Option 1: a single large-area FPC without restriction on complex circuitry (Fig. 3(a)). No internal connectors are required but this is the most complex option to manufacture and would require significant investment in manufacturing plant to achieve handling capability for large panel sizes.

Option 2: a complex circuitry core with detachable, simply processed arms (Fig. 3(b)). This reduces the area of laminate requiring complex processing but doubles the number of connectors required over option 1. Current equipment may be able to handle the panel sizes.

Option 3: a single, simply processed large-area FPC with complex circuitry on small patches (Fig. 3(c)). This reduces the area requiring complex processing still further over option 2, while requiring fewer connectors. Some investment in large-area-capable processing equipment would be required although less than for option 1.

Option 4: multiple FPCs interconnected at attachment points (Fig. 3(d)). This option requires the least modification of existing processing equipment. The smaller size of panels also means that material utilization is likely to be the most efficient. Processing costs can be further reduced by restricting the number of constituent FPCs that require complex processing. The number of connectors required is probably intermediate between those for options 2 and 3 . 


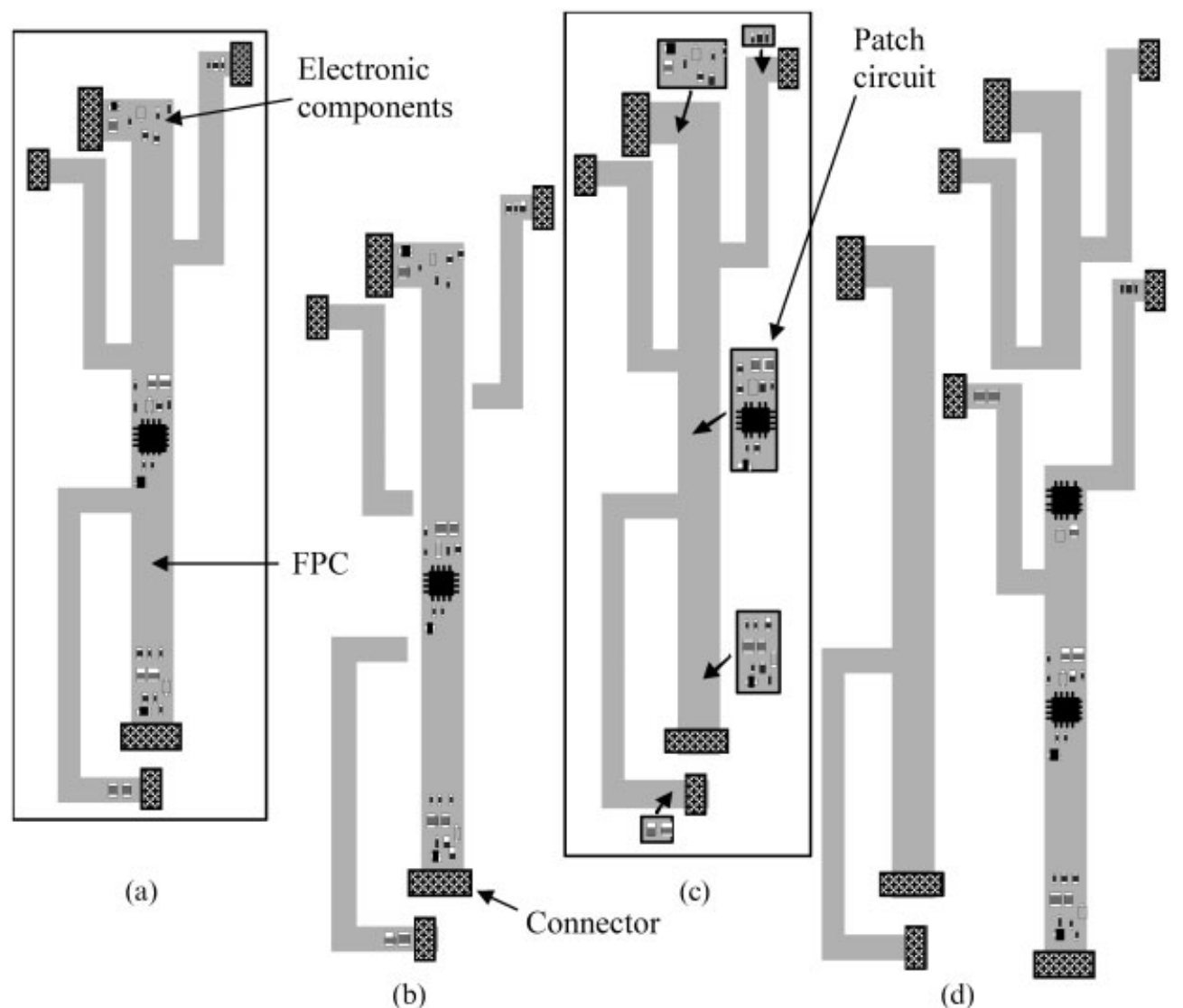

Fig. 3 Automotive FPC harness construction options. See text for a description

For all construction options the arms of the FPC can be laid out on the panel to maximize material usage. The FPC is made to adopt the correct threedimensional configuration on assembly into the vehicle by folding the arms into position. Extra components such as clips may be required to retain the folds.

\section{DESIGN SPECIFICATIONS OF THE DEMONSTRATORS}

A real automobile wire harness was chosen as the basis of the exercise in order to prove the practicality of the construction options. The exercise was carried out by working from the layout diagram and connectivity table for the harness. The original functional specifications of the demonstrators were the following:

(a) to support the point-to-point interconnection functionality of the wire harness;

(b) to support the current-carrying capacity specified for each circuit;

(c) to support the physical positioning of the connectors; (d) to add extra functionality to the harness to illustrate the added value of using an FPC.

An IP harness for a Daewoo Nubira, a small family car (a US compact car) was chosen as the basis of the demonstrators. The IP harness was chosen because it is the most complex in the car and hence represents the severest test for future large-area FPC harnesses. In addition the Nubira J-100 carried higher-end features for the time such as anti-theft, an anti-lock braking system, and airbags, adding further complexity to the IP harness. A sample of, and engineering data for, a model 96237581k IP harness for a left-hand drive, the North American variant of the J-100, was available to the project. The engineering data consisted of the harness layout diagram, the point-to-point connection table, and the electrical load analysis report. The harness consisted of approximately 200 wires, 43 connectors, and six splice packs, and weighed $2.3 \mathrm{kgf}$.

In order to be able to manufacture a space model the demonstrator designs were limited to the capabilities of currently available equipment. This meant a maximum panel area of $1 \mathrm{~m}$ by $0.75 \mathrm{~m}$. The space model was to be realized in one of the standard laminates typically processed by In2Con- 
nect, consisting of $35 \mu \mathrm{m}\left(1 \mathrm{oz} / \mathrm{ft}^{2}\right)$ copper foils laminated on both sides of a $125 \mu \mathrm{m}$ PET base film with a polyester adhesive $15 \mu \mathrm{m}$ thick. A key set of parameters for the detailed design were the design rules for track widths and spacing. Track ampacity ratings were based on proprietary data from powered FPC tests made available to the project and calculated at approximately $1 \mathrm{~A} / \mathrm{mm}$. Two standard track widths were chosen: $1.3 \mathrm{~mm}$ for currents of $1 \mathrm{~A}$ and less, and $3.84 \mathrm{~mm}$ for currents greater than $1 \mathrm{~A}$. Track spacings were set at $1 \mathrm{~mm}$. These choices matched the pitches of available FPC connectors and thus simplified the design task. As dedicated automotive FPC connectors do not yet exist, generalpurpose crimped connectors were used. These consist of a number of contacts, as shown in Fig. 4, which are assembled in rows in a plastic housing. Each contact has a set of crimping tines at one end. To attach a contact to a copper track the tines are forced through the laminate from underneath and are then folded over to make an electrical connection to the track on the top side. These parts are therefore not capable of handling double-sided connections, and so tracks leading to the connectors had to be on one side of the circuit only, leading to a reduction in space utilization efficiency. Again, for simplicity, the variety of connectors used was restricted to 5-way, 10-way, 15-way, and 20-way connectors.

Demonstrator 1 contained elements of construction options 1-3. It consisted of a single large-area circuit with double-sided processing and throughhole interconnections confined to a central area. The original intention was to implement construction option 1 , because it is the most reliable and the furthest conceptually from a wire harness. However, a review of the processing equipment available and

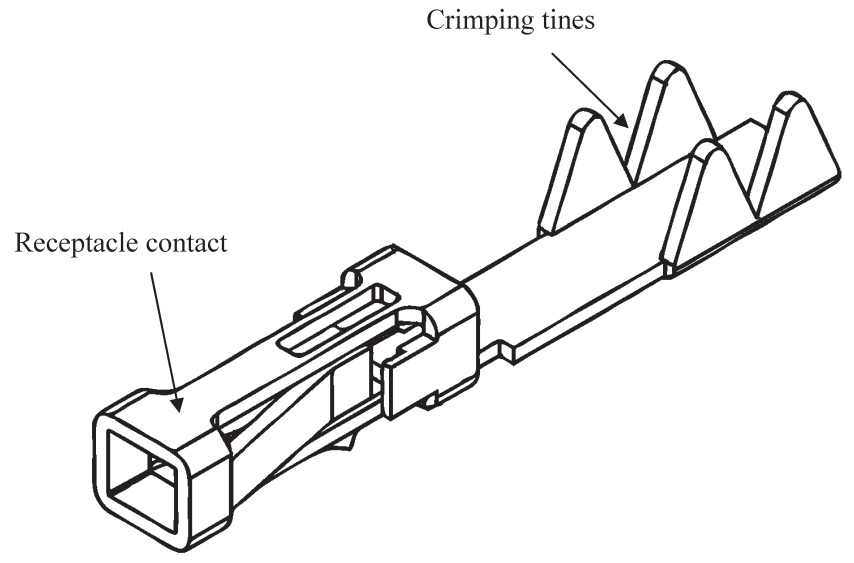

Fig. 4 Crimp-type contact for an FPC connector (AMP 487406-4) the limitations of the design software available to the project led to the eventual concept, as described in the detailed design section below. Demonstrator 2 was an attempted implementation of construction option 4 (multiple smaller FPCs), chosen because it has the lowest estimated manufacture and investment costs and is thus the most likely candidate for near-term adoption.

In addition, a courtesy light controller, i.e. a small circuit extra to the specification of the J-100 wire harness and incorporating surface-mounted components, was included as an illustration of the added capabilities of an FPC over wire. The circuit was carried on a smaller FPC referred to as a patch circuit, $50 \mathrm{~mm}$ by $58 \mathrm{~mm}$ in area, and was connected by crimping to the main FPC.

The original design intent of supporting the full current-carrying capability of the wire harness was weakened after making initial estimates of the widths of laminate that would be required using the $1 \mathrm{~A} / \mathrm{mm}$ with $1 \mathrm{~mm}$ spacing rule and single-sided copper. It was decided to cap the currents supported at $4 \mathrm{~A}$; i.e. all circuits with higher current ratings were assigned a track width of $3.84 \mathrm{~mm}$. This still allows 73 per cent of circuits to be supported with a suitable track width, as can be seen from Fig. 5, which shows the cumulative distribution, by current ratings, of the number of circuits with each rating. The sum of track and spacing widths required to support all the circuits at or below a given current rating is also plotted as a percentage of the 100 per cent value of $1.16 \mathrm{~m}$ for single-sided laminate. Around 45 per cent of the width of laminate is required to support just 10 per cent of the total number of circuits, for currents of $9 \mathrm{~A}$ and above. Current ratings of higher than $10 \mathrm{~A}$ were mostly for the failure conditions of

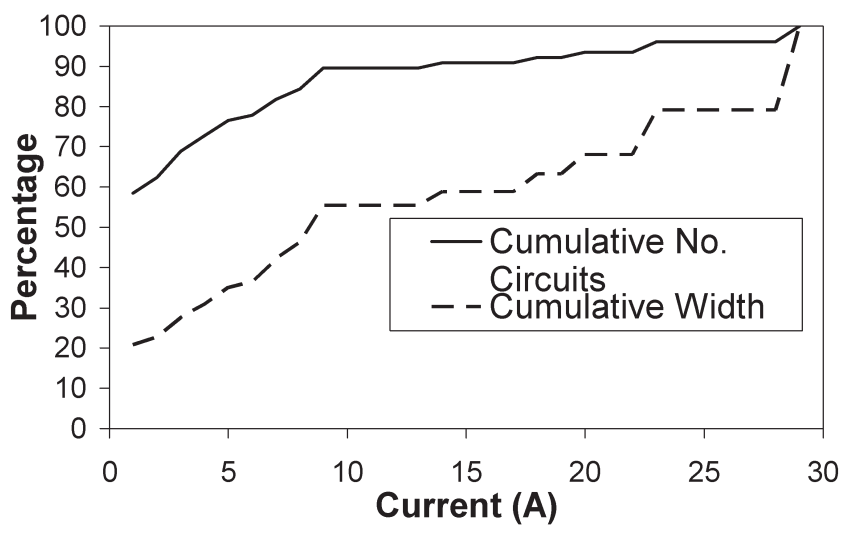

Fig. 5 Cumulative distributions by current rating of the number of circuits, and the total width of laminate required to carry the circuits 
stalled electric motors, e.g. the windscreen wipers and the cockpit blower fan.

\section{DETAILED DESIGN OF DEMONSTRATOR 1}

The electrical layout was carried out in a Mentor Graphics Board Station (version 8), a dedicated electrical computer-aided design (ECAD) package, because of the complexity of the track-routeing task. The normal practice for the relatively simple conventional automotive FPC circuits is to lay out the track patterns manually in a computer-aided design (CAD) package. The schematic representation of the electrical circuit within Mentor was very simple, consisting mostly of single connections between pairs of pins corresponding to a single wire in the harness joining two connectors. The pins were represented using a connector symbol from the Board Station parts library. Multiple connector symbols, having the same assigned reference name, were used to represent the physical connector of that name. Each connection was classified as a high- or low-current net type, allowing the appropriate track width to be assigned at the physical drawing generation stage. A connector was also defined for the patch circuit. An example section of the harness schematic diagram is shown in Fig. 6. With each connector type was associated a physical pad geometry which could accommodate the connector crimp terminals.

The initial design approach was to place the connectors in positions within a $1.0 \mathrm{~m}$ by $0.75 \mathrm{~m}$ outline approximating those specified in the harness layout diagram. The electrical traces were then

Automotive Connector to Connector Representation

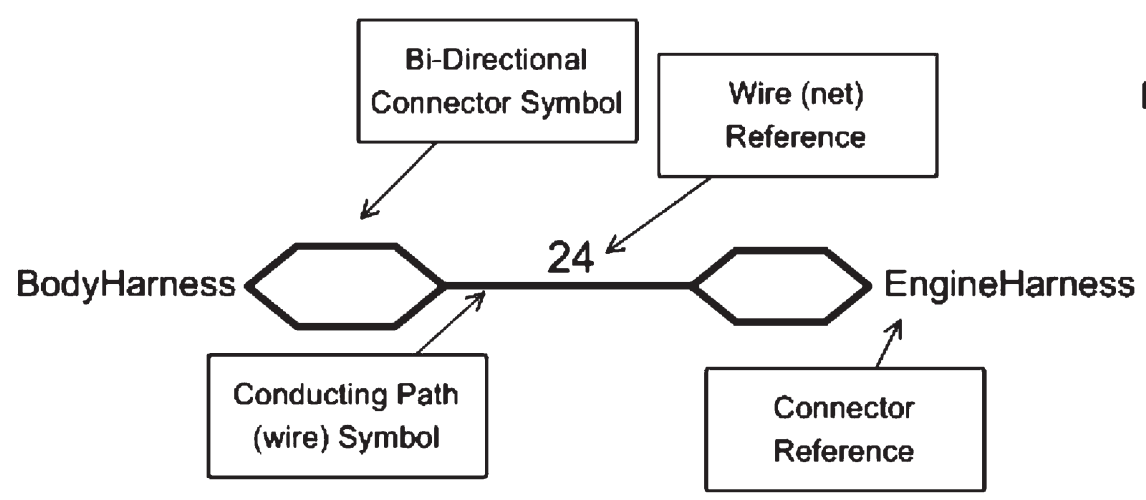

Automotive Connector to Splice Representation

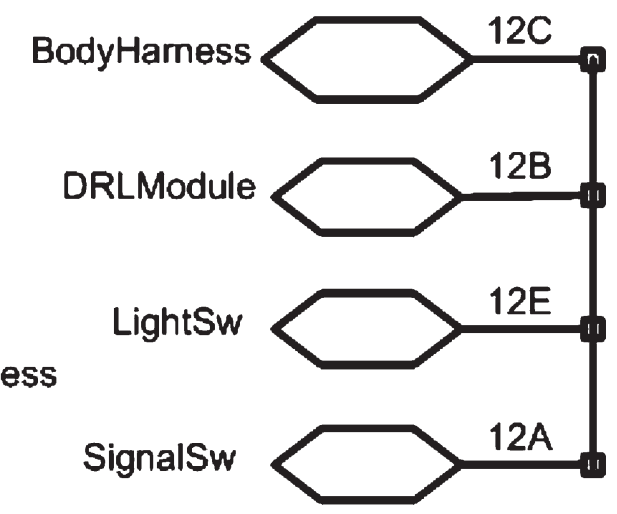

SPLICE PK1

Fig. 6 Section of the harness schematic diagram in the Mentor Graphics Board Station (DRL, daytime running light; Sw, switch) 


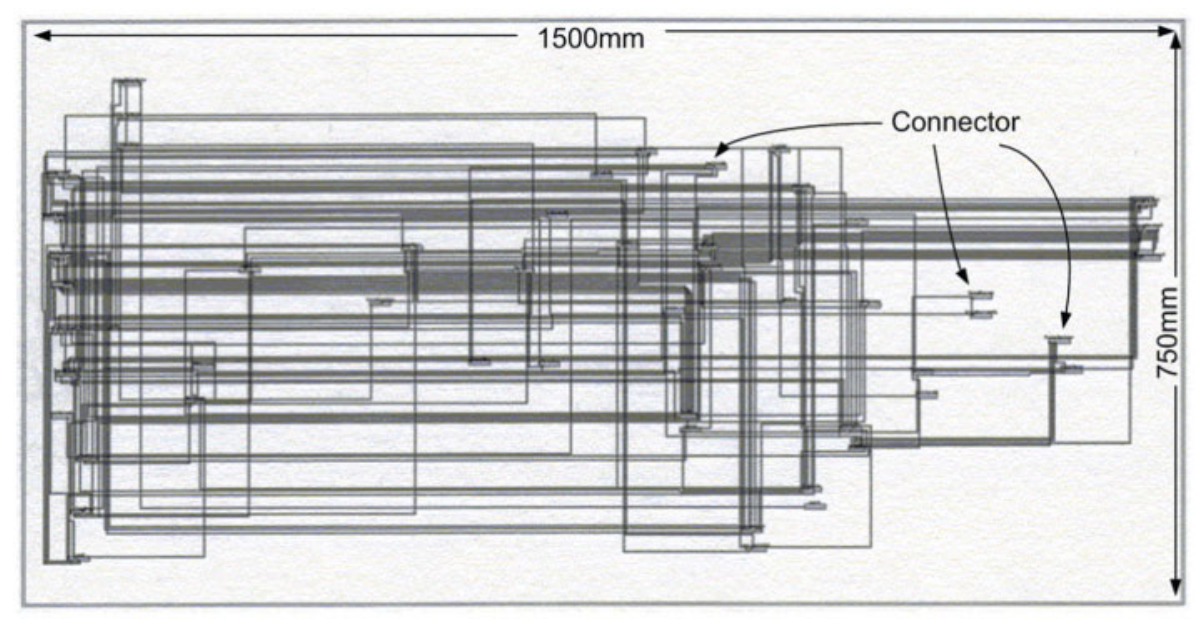

Fig. 7 Spatially unrestricted trace routeing for demonstrator 2

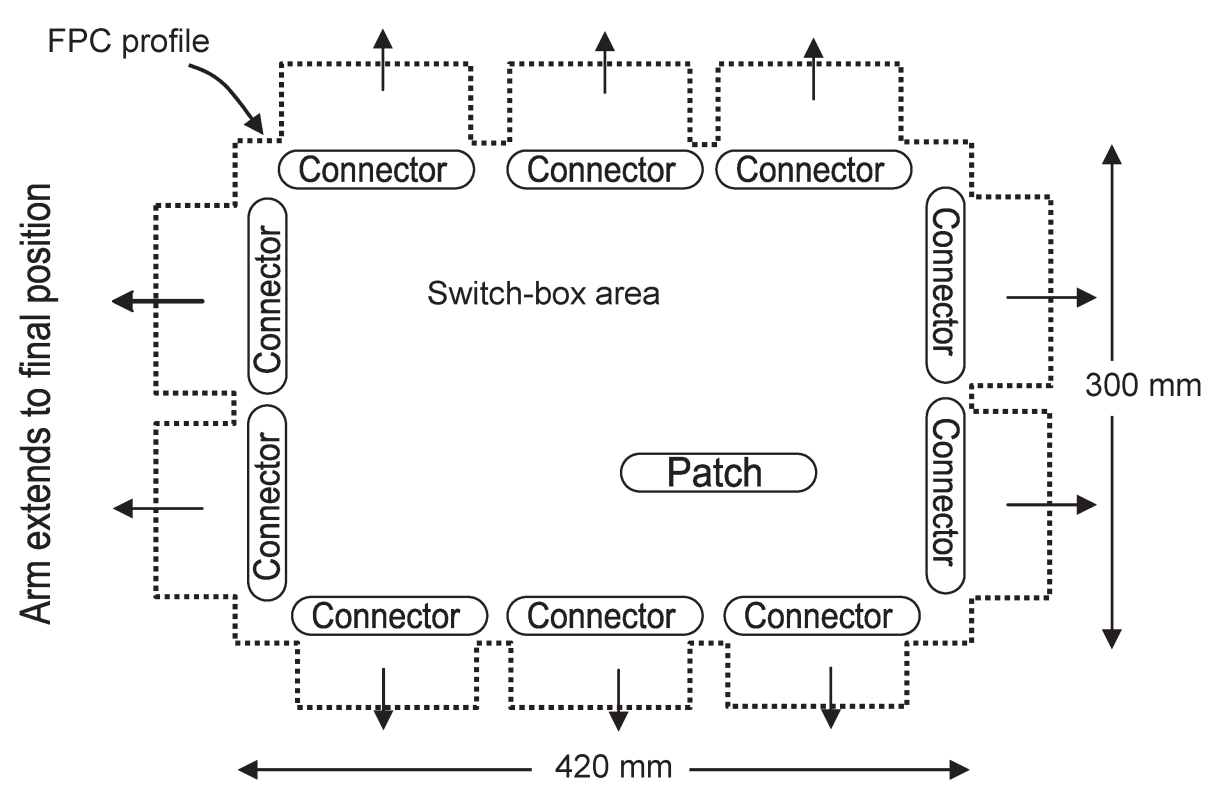

Fig. 8 Switch-box routeing approach for demonstrator 2

switch-box periphery to the final connector position. The autorouter was found to be not capable of carrying out this task. The arms were single sided to accommodate the FPC connectors (see previous section) and thus had no side-to-side interconnects.

The area of the switch box, $420 \mathrm{~mm} \times 300 \mathrm{~mm}$, was determined by the connector dimensions. It is possible that this area could be reduced because there was some waste width in the connectors. This partly comes from unused pins on the standard width connectors, and partly from the fact that the pin pitch on a connector is determined by the highest track width to be handled. Thus a connector with a single high-current track has a pitch of $4.84 \mathrm{~mm}$ even if all the other tracks are low current rated. The greatest reduction in area, however, would come from assuming that the connectors could handle a double-sided arm, thus halving the arm widths.

\section{DETAILED DESIGN OF DEMONSTRATOR 2}

Demonstrator 2 was conceived as a set of separate, simply processed, double-sided laminate FPC components, with a single double-sided complex-processed FPC with side-to-side connections and which would carry components and hard-to-route traces. The allocation of traces to FPC components was achieved manually by identifying connector pairs sharing the largest number of connections, and placing these on the first, simply processed FPC. 
Connectors sharing fewer connections were placed on subsequent, simply processed FPCs, and the complex-processed FPC was used to carry traces that could not be placed on the other layers. A total of six component FPCs were used. The connectors were assumed to be able to accept multiple circuit layers and to be able to support side-to-side interconnection for the simply processed FPCs. No such connectors currently exist.

The trace-layer allocation method was time consuming and produced an impractical solution, since the underlying assumption within the trace-layer allocation method is the availability of sufficient connector-to-connector pairs to form wide FPC arms. In fact, most connector-to-connector pairs were limited to a single trace. This implies that multiple single-trace-wide FPC arms would have to be handled and inserted into a single connector. In the worst case, eight layers were routed to a single connector.

\section{SPACE MODEL}

The space model was manufactured from the demonstrator 1 design. Although the panel size had been chosen to fit the maximum width capability of the automotive FPC etch line available to the project, other equipment at the same facility did not have the area capability. The space model was therefore manufactured in stages at a set of other sites not normally involved in FPC manufacture. That this was possible demonstrates that equipment is already available that can handle large-area FPCs even if not currently used for that purpose. Up to ten-off panels were processed, as outlined in Table 1.

The artwork from Mentor Graphics was output as a dxf file and passed to In2Connect. While able to read the dxf file, In2Connect could not import the information into their CAD software for further processing and so had to redraw the artwork by hand. The implications of this ECAD-CAD incompatibility issue are discussed in section 9. The redrawn CAD artwork was used to generate both the phototool and the file to drive the laser profiler. At this stage the land pad patterns for the patch circuit splice connections were also added. A length of base laminate was cut into panels by hand and printed with etch resist on a flatbed screen printer usually used for commercial graphics. The area of panel was not particularly large compared with the printer company's capability. Ten-off panels were taped together and taken through the etch-and-strip stage at In2Connect on reel-to-reel spray-processing equipment. The panels were then separated again and drilled on a dual-head printed-circuit-board drilling machine at Leicester Circuits, which had the required area capability. The computer-numerically controlled table to drive the drilling machine at Leicester Circuits was generated from Mentor Graphics, but an error arising during the process of redrawing the artwork meant that the tooling alignment holes (ECAD data) did not match the fiducial patterns on the artwork (CAD data). The problem was resolved by manually aligning the panels on the drill platen.

One panel was selected out of the ten to be powered for display purposes. This required com-

Table 1 Manufacturing process for the space model

\begin{tabular}{|c|c|c|c|}
\hline Process & Company or organization & $\begin{array}{l}\text { Number of } \\
\text { panels treated }\end{array}$ & Comments \\
\hline $\begin{array}{l}\text { Trace layout, outline generation } \\
\text { (ECAD) }\end{array}$ & Loughborough University* & 10 & $\begin{array}{l}\text { ECAD package Mentor } \\
\text { Graphics Board Station, } \\
\text { outputs dxf file } \\
\text { and drill table }\end{array}$ \\
\hline CAD layout & $\begin{array}{l}\text { In2Connect* (reel-to-reel FPC } \\
\text { manufacturer) }\end{array}$ & $\mathrm{N} / \mathrm{A}^{\dagger}$ & $\begin{array}{l}\text { ECAD dxf output redrawn } \\
\text { using CAD package }\end{array}$ \\
\hline Phototool production & Photodata & $\mathrm{N} / \mathrm{A}^{\dagger}$ & \\
\hline $\begin{array}{l}\text { Screen print etch resist pattern } \\
\text { on base laminate }\end{array}$ & $\begin{array}{l}\text { Polyprint Plastics (retail and display } \\
\text { printer) }\end{array}$ & 10 & $\begin{array}{l}\text { Etch resist ink supplied by } \\
\text { In2Connect }\end{array}$ \\
\hline Through-hole drilling & $\begin{array}{l}\text { Leicester Circuits (printed-circuit- } \\
\text { board manufacturer) }\end{array}$ & 10 & \\
\hline $\begin{array}{l}\text { Etching of copper and strip } \\
\text { resist }\end{array}$ & In2Connect* & 10 & \\
\hline Through-hole interconnection & Loughborough University* & 1 & Hand soldered \\
\hline Coverlay lamination & Polyprint Plastics & 4 & \\
\hline Profiling & In2Connect* & 4 & Laser profiled \\
\hline Connectorization & In2Connect* & 2 & \\
\hline
\end{tabular}

*Project partner.

${ }^{\dagger} \mathrm{N} / \mathrm{A}$, not applicable. 
pleting the electrical continuity for selected circuits by filling the through holes with tin-lead solder by hand with a soldering iron. The method is unlikely to be practical for mass manufacture because the solder did not wet the side walls and so did not naturally pass through the holes, even though the polyester was only $125 \mu \mathrm{m}$ thick (while the diameter of the through-hole was $0.6 \mathrm{~mm}$ ). Four panels including the powered panel were laminated with a $50 \mu \mathrm{m}$ polyester coverlay and profiled, and two including the powered panel were connectorized and had the patch circuit crimped on.

The final connectorized FPC with a patch circuit weighed $400 \mathrm{gf}$, as against $2.3 \mathrm{kgf}$ for the J-100 Nubira wire harness. This weight included those of the connectors and some fixings. The cost of manufacture of the space model was estimated at $£ 23$ by In2Connect Ltd (lead project partner and automotive FPC manufacturer) based on a production volume of $2 \times 10^{6}$ units per year, as against $£ 50-60$ for the wire harness (estimate supplied by Yazaki Europe Ltd, wire harness manufacturer and project partner). On the display space model, shown in Fig. 9, the meters and lights of the meter set, the glove-box light and switch, and the crimped-on patch circuit were powered and functioned correctly.

\section{DISCUSSION}

The major lesson learned from the design exercise is that the track layout task and the physical architec- ture of a large-area FPC are tightly coupled and cannot be considered in isolation from each other. The structure of demonstrator 1 was determined by the capabilities of the routeing software, while the initial conception of demonstrator 2 proved to be impractical. Demonstrator 1 also appears to be not practical from the viewpoint of fitting into the vehicle. While methods of assembly of a large-area FPC harness into a car were not addressed in detail by the project, it was mooted that the car trim could be used as a carrier, e.g. the fascia. A similar concept has already been used for mounting flexible flat cables onto roof linings [17]. Mounting on the trim would take advantage of the flatter profile of an FPC while providing a convenient method of insertion into the vehicle. For this assembly method the ideal outline of the FPC would be long and narrow.

Demonstrator 1 also failed to reproduce the full current-carrying capacity of the wire harness. However, as stated in the introduction, the FPC is not envisaged to be a drop-in replacement for wire. The demonstrators and space model can be seen as the first step in an iterative process of establishing what a large-area FPC might realistically look like. Changes to the automotive electrical system design may be necessary both to take advantage of and to accommodate an FPC as a large-area interconnection solution. An example of a change that might solve both the switch-box problem and the current capacity problem is the use of 'soft switches', i.e. switches which do not carry the power current to the

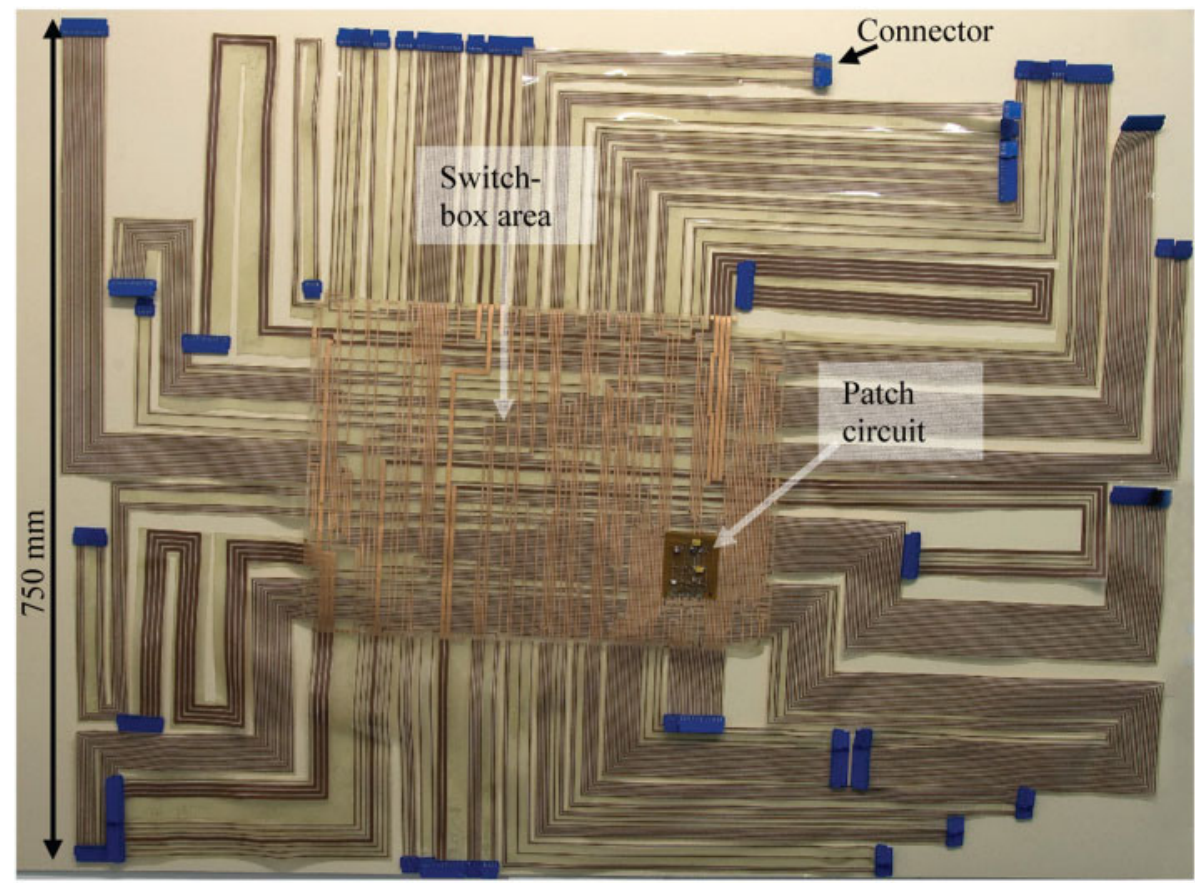

Fig. 9 Display version of the space model, with the connectors and the patch circuit 
operated device but which instead operate a relay. Power would be supplied by a ring main or similar arrangement. This concept is similar to automotive networks such as CANBUS [18] but would have a lower cost since only a relay rather than a microcontroller is required to be associated with each device. A soft switch architecture would take advantage of the ability of FPC to carry low-weight low-current tracks with consequently much higher track densities, without affecting physical strength.

Another problem identified in the design exercise was the inadequacy of current design tools for a complex circuit-board outline. Although the Specctra auto-router within Mentor has been noted as highly capable with printed-circuit boards and widely used for development of complex devices [19], it was unable to cope with the multiple-armed outline of the demonstrator. It was also unable to route a simple set of parallel tracks along an arm. A further problem with current design tools is with the lack of a capability for the exchange of data between ECAD and CAD packages.

The design exercise represents the first step in an iterative process to determine the best form for large-area FPC harnesses. An FPC in this application is a substitution technology for well-established and well-understood wire. Edwards [20] argued that the long lead times involved in technology substitution remains a major constraint on change in the automotive industry. The main reasons for this are as follows.

1. Working prototypes, although much reduced in quantity, are still required to demonstrate performance, despite sophisticated computer modelling and simulation techniques.

2. The ability to process the materials needs to be demonstrated, and that is best achieved physically, under conditions normally experienced in production.

3. Designing, developing, manufacturing, and commissioning new tooling and production equipment continues to be a significant drain on time and resources.

From this point of view the best route forwards for FPC harnesses is substitution for less complex parts of the wire harness. This has the benefits of requiring lower investment costs as existing FPC and other production equipment can be used, as shown by the space model manufacture exercise. Use of smaller FPC harnesses in production model cars in nonsafety critical applications would allow field reliability data to begin to be built up, while providing a commercial incentive for the development of connectors, mounting methods, and design tools.

\section{CONCLUSIONS}

A detailed design exercise and a manufacturing process trial for a complex large-area flexible printed circuit (FPC) automotive interconnection harness has been described. The designs were based on the engineering specification for the IP wiring harness of a midrange passenger car. Two generic design concepts were pursued in the design exercise. The first, a single large-area FPC fitting within a panel of area $1 \mathrm{~m}$ by $0.75 \mathrm{~m}$, supported the wire harness geometry, all point-to-point interconnections, and current ratings up to $4 \mathrm{~A}$. The second, intended to be a collection of smaller FPCs that could be manufactured on existing FPC process lines, was found not to be practical as originally conceived.

A physical implementation of the single large-area FPC design was made in stages at different company sites. The implementation incorporated an active electronic circuit made up of surface-mounted components, in order to demonstrate the ability of an FPC harness to support intelligence. Some of the equipment used for the manufacturing is not normally used for FPC or electrical circuit manufacture. However, the fact that equipment with the size capability required for the manufacture of large-area automotive FPCs already exists means that the amount of development and hence investment required to create a large-area FPC manufacturing line are not as great as might otherwise be the case.

The major implication of the exercise is that the interconnection task at least partly dictates the physical architecture of the flexible printed circuit, and hence the two cannot be considered separately. In addition, it seems likely that a direct replacement of wiring harnesses with an FPC in the vehicle electrical architecture would neither be feasible nor take full advantage of the capabilities of FPCs. Currently available ECAD design tools were shown to be inadequate for the task of handling the layout task within the complex outline of a large-area FPC. In view of these complexities and of the long lead times for technology substitution in the automotive industry, it is likely that the best route forwards for development of automotive FPC electrical interconnection harnesses is substitution for smaller and less complex parts of the vehicle wire harness, e.g. in the door. Commercial offerings of this sort are already available [21]. 


\section{ACKNOWLEDGEMENTS}

The authors would like to thank In2Connect Ltd, Yazaki Europe Ltd, GTS Flexible Materials Ltd, and P. Selwood for their collaboration. This work was undertaken as part of the FLEXELEC project, sponsored by the Engineering and Physical Sciences Research Council under the Foresight Vehicle Initiative.

(C) Authors 2010

\section{REFERENCES}

1 Leen, G. and Heffernan, D. Expanding automotive electronic systems. Computer, 2002, 35, 88-93.

2 Miller, J. and Nicastri, P. The next generation automotive electrical power system architecture: issues and challenges. In Proceedings of the 17th Digital Avionics Systems Conference (DASC 1998), Seattle, Washington, USA, 31 October-7 November 1998, pp. I15/1-I15/8 (IEEE, New York).

3 Results of the review of the Community Strategy to reduce $\mathrm{CO}_{2}$ emissions from passenger cars and light-commercial vehicles. Communication from the Commission to the Council and the European Parliament, COM(2007) 19 final, \{SEC(2007) 60\}, $\{$ SEC(2007) 61\}, Commission of the European Communities, Brussels, 2007.

4 BBC News, US Senate seeks fuel efficiency, 2008, available from http://news.bbc.co.uk/1/hi/world/ americas/6229114.stm (access date 14 January 2008).

5 Lindahl, B. R. Opportunities for integration with flexible circuitry in instrumentation displays. SAE paper 950961, 1995.

6 Astler, C. New connections for automobiles. Automot. Engng Int., 2001, 109, 77-80.

7 Cottrill, M. C. W., Jaggernauth, W. A., Webb, D. P., Palmer, P. J., Conway, P. P., and West, A. A. Foresight vehicle: large area flexible circuits for automotive applications manufacturing technology, a review of process options. SAE paper 200201-1127, 2002.

8 Carrott, A. J., West, A. A., Conway, P. P., and Cottrill, M. C. W. Business case modelling of large area flexible circuits in the foresight vehicle program. SAE paper 2002-01-1128, 2002.

9 Jaggernauth, W. A., Webb, D. P., Cottrill, M. C. W., Palmer, P. J., Conway, P. P., and West, A. A. Foresight vehicle: specification and acceptability criteria for copper-clad dielectric materials used in large automotive flexible printed circuits. SAE paper 2002-01-1129, 2002.

10 Webb, D. P., Cottrill, M. C. W., Jaggernauth, W. A., West, A. A., Palmer, P. J., and Conway, P. P.
Foresight vehicle: physical media for automotive multiplex networks implemented on large area flexible printed circuit boards. SAE paper 2002-011130, 2002.

11 Webb, D. P., Jaggernauth, W. A., Cottrill, M. C. W., West, A. A., Conway, P. P., and Palmer, P. J. Electromagnetic compatibility performance of large area flexible printed circuit automotive harness. Proc. IMechE, Part D: J. Automobile Engineering, 2004, 218(7), 667-673. DOI: 10.1243/09544070 41580102.

12 Jennings, P., Ball, R., and Lever, P. Using statistics to reduce the uncertainty in system level susceptibility testing. In Symposium Record of the IEEE 1995 International Symposium on Electromagnetic compatibility, Atlanta, Georgia, USA, 14-18 August 1995, pp. 47-50 (IEEE, New York).

13 Ng, F. M., Ritchie, J. M., and Simmons, J. E. L. The design and planning of cable harness assemblies. Proc. IMechE, Part B: J. Engineering Manufacture, 2000, 214(10), 881-890. DOI: 10.1243/095440500 1517964.

14 Engbring, J. and Renner, G. Optimized design of flat wiring systems. SAE paper 2003-01-0228, 2003.

15 BS AU 88a:1985. Recommendations for ratings for light duty cables for automobile use, 1985, pp. 1-4 (British Standards Institution, London).

16 Kassakian, J. G., Wolf, H., Miller, J. M., and Hurton, C. J. The future of automotive electrical systems. In Proceedings of the IEEE Workshop on Power electronics in transportation, Dearborn, Michigan, USA, 24-25 October 1996, pp. 3-12 (IEEE, New York).

17 Fujisaki, A. and Samitsu, N. Development of flexible flat cable harnesses for automobile roof modules. Furukawa Rev., 2002, 21, 87-91.

18 ISO 11898:1993(E). Road vehicles - interchange of digital information - controller area network (CAN) for high-speed communication, 1993 (International Organization for Standardization, Geneva).

19 Grigoriev, V. and Panchak, R. The comparative analysis of automatic trace routing in PCAD and OrCAD. In Proceedings of the Second International Conference on Perspective technologies and methods in MEMS design (MEMSTECH 2006), Lviv, Ukraine, 24-27 May 2006, pp. 143-145 (IEEE, New York).

20 Edwards, K. L. Strategic substitution of new materials for old: applications in automotive product development. Mater. Des., 2004, 25, 529-533.

21 Freudenberg \& Co., Freudenberg at the IAA, 2005, available from http://www.freudenberg.com/ ecomaXL/index.php?site=FCO_en_topthema_ detail\&udtx_id=1701 (access date 20 February 2009). 